\title{
A SUPERAÇÃO DA CONCEPÇÃ̃ LIBERAL DE LIBERDADE EM HANNAH ARENDT
}

\author{
Edson Kretle ${ }^{1}$ \\ Universidade Federal do Espírito Santo (UFES) \\ Instituto Federal do Espírito Santo (IFES) \\ https://orcid.org/0000-0003-1733-1925 \\ E-mail: edson.santos@ifes.edu.br \\ Ricardo Corrêa de Araujo ${ }^{2}$ \\ Universidade Federal do Espírito Santo (UFES) \\ https://orcid.org/0000-0002-0431-8599 \\ E-mail: rcaerca@uol.com.br
}

\section{RESUMO:}

Este artigo pretende confrontar duas noções acerca da noção de liberdade, temática central na Filosofia Política. De um lado, partiremos de algumas reflexões do liberalismo político, onde no primeiro momento, exploraremos a obra Dois Conceitos de Liberdade (Two Concepts of Liberty), de Isaiah Berlin. Para esse autor a liberdade negativa (negative liberty "estar livre de") e, não a liberdade positiva (positive liberty - "estar livre para"), deve ser a maior preocupação dos corpos políticos, ou seja, o Estado deve existir para evitar que a liberdade individual seja reduzida pela própria interferência do Estado ou de outros sujeitos. De encontro a essa ideia, e ancorados em Arendt, desejamos sustentar que um dos grandes problemas do liberalismo político é a não ação (negative liberty), isto é, a falta de participação do cidadão nos assuntos e nas decisões políticas. Ao mostrar isso, defenderemos em Arendt o papel central da liberdade positiva (political freedom) da ação e da fala, e, consequentemente, a possibilidade de um republicanismo cívico como alternativa ao isolamento e apatia políticas gestados pela liberdade burguesa, uma vez que, para Arendt, a aposta de Berlin e da tradição liberal são insuficientes para pensarmos os acontecimentos da política contemporânea.

PALAVRAS-CHAVE: Política; Liberdade; Liberalismo; Cidadania; Arendt.

\section{THE OVERCOME OF THE LIBERAL CONCEPTION OF LIBERTY BY HANNAH ARENDT}

\begin{abstract}
:
This article intends to confront two notions about the notion of liberty, central theme on Political Philosophy. On one side, we'll start on some observations of political liberalism, where in the first moment, we'll explore the book "Two Concepts of Liberty" by Isaiah Berlin. To this author the negative liberty - "being free of" and, not the positive liberty "being free to", should be the biggest worry of political bodies, that is, the State must exist to avoid that individual liberty is reduced by the own state interference or other subjects. Meeting this idea, and anchored in Arendt, we want to sustain that one of the big problems about political liberalism is the not action (negative liberty), that is, the lack of participation from the citizens on subjects and on political decisions. Showing this, we will defend in Arendt the central role of positive liberty (political freedom) of action and speak, and, thereafter, the possibility of a civic republicanism as an alternative to the isolation and the political apathy conceived by the bourgeois liberty, since, to Arendt, Berlin's bet and the liberal tradition are unsatisfying to think the events of contemporary politics.
\end{abstract}

KEYWORDS: Politics; Liberty; Liberalism; Citizenship; Arendt.

\footnotetext{
${ }^{1}$ Doutorando em Filosofia pela Universidade Federal do Espírito Santo (UFES), Vitória - ES, Brasil. Professor do Instituto Federal do Espírito Santo (IFES), Venda Nova do Imigrante - ES, Brasil

${ }^{2}$ Doutor em Filosofia pela Universidade Federal do Rio de Janeiro (UFRJ), Rio de Janeiro - RJ, Brasil. Professor de Filosofia da Universidade Federal do Espírito Santo (UFES), Vitória - ES, Brasil.
}

KRETLE, Edson; ARAUJO, Ricardo Corrêa de. A superação da concepção liberal de liberdade em Hannah Arendt. Griot : Revista de Filosofia, Amargosa - BA, v.20, n.2, p.202-214, junho, 2020. 


\section{Introdução}

No uso comum da linguagem, geralmente, usamos o termo política, como a arte de gerir o destino da cidade, nesse sentido, o termo Politikos, deriva de Pólis. Atualmente, múltiplos são os caminhos que envolvem esse tema nas Ciências Humanas, conceitos se entrelaçam; política e poder, coerção e persuasão, autoridade e autoritarismo, Estado e governo, e mais uma vasta gama de abordagens práticas e conceituais. Nosso escopo aqui, porém, se limitará ao tema da liberdade negativa e positiva, suas possibilidades e limites nas democracias liberais. Entretanto, para início de conversa, advertimos que seria impossível abordar a complexidade do conceito de liberdade e suas diversas facetas no pensamento político contemporâneo, pois:

dificilmente seria justo dizer que somente o pensamento político liberal é fundamentalmente interessado na liberdade; é pouco provável que haja uma escola de pensamento político em nossa história que não seja centrada em torno da ideia de liberdade, por mais que o conceito de liberdade possa variar com diferentes escritores e em diferentes circunstâncias políticas (ARENDT, 2014, 135).

O liberalismo pode ser de forma muito sucinta e até arriscada, com uma "doutrina que tomou para si a defesa da liberdade no campo político, ético e econômico" (ABBAGNANO, 2014. p.696). A tradição liberal nasce em torno de alguns valores que orientam a vida do homem em sociedade, e que possibilitam, em certo sentido, seu convívio como um ser social e político. Paulatinamente, com muitas lutas e conquistas, temos no âmbito jurídico um ideal pautado nos direitos humanos e na liberdade individual. Na esfera moral, constatamos o pluralismo e a tolerância dada à diversidade de modos de vida aos quais os indivíduos se tornam agentes responsáveis pelos seus próprios destinos, e ao mesmo tempo, escolhem diante das mais variadas doutrinas, convicções e opiniões em assunto de moral e de religião porque "nem todas as coisas boas são compatíveis, muito menos todos os ideais da humanidade" (BERLIN, 1969, p28).

Em se tratando do poder público, somos herdeiros da noção republicana de um governo limitado e de leis, bem como a orientação que o Estado deve ser neutro diante de toda e qualquer concepção de bem. Para representar as sociedades liberais na qual a cultura pública é marcada por diferentes doutrinas morais abrangentes, Rawls alcunha esse episódio como o fato do pluralismo. Assim sendo,

uma hipótese crucial do liberalismo consiste no fato de os cidadãos iguais terem concepções diferentes, e efetivamente incomensuráveis e irreconciliáveis, do bem. Numa sociedade democrática moderna, a existência de modalidades de vida tão diversas é considerada uma circunstância normal que só pode ser suprimida pelo uso autocrático do poder do Estado (RAWLS, 2000, p.160).

Portanto, vale ressaltar que a identidade liberal é constitutiva do ocidente democrático. Dá mesma forma que "é impossível saltar a própria sombra" (Hegel), desse modo, encontraríamos muitas dificuldades para pensarmos outra "forma de vida" (Wittgenstein) que não seja a tradição liberal abalizada numa democracia constitucional. Mesmo com todos os problemas de direitos e oportunidades ainda não efetivados pelo discurso liberal, esse ideal se consolidou como o paradigma político desde a modernidade.

Repetimos que neste artigo temos apenas como finalidade confrontar as teses de Berlin sobre a liberdade positiva e negativa, e em seguida, retomar algumas críticas e propostas de superação elaboradas por Hannah Arendt, para assim conjecturar sobre como a dicotomia de Berlin pode ou não, nos auxiliar no entendimento, debate e defesa da liberdade em tempos de 
crise e constantes questionamentos do paradigma democrático. Para o fim almejado, dividiremos este artigo em duas partes. No primeiro momento serão exploradas as críticas de Berlin à noção de liberdade positiva, bem como, sua defesa da liberdade negativa. No segundo momento, procuraremos explorar a visão arendtiana acerca da liberdade, a fim de acenar para algumas críticas da autora à concepção de Berlin e estendendo-a ao liberalismo político. Por fim, tentaremos mostrar que para superar a dicotomia proposta por Berlin, será preciso encontrar nas teses de Arendt, espaço para os dois tipos de liberdade, bem como uma possibilidade de pensarmos uma cidadania republicana centrada na participação do cidadão nas decisões políticas pela criação do Estado-conselho.

Embora o autor em questão seja Berlim, para situarmos a concepção de liberdade confrontada aqui, iniciaremos utilizando a clássica definição proposta por Benjamim Constant, no seu discurso proferido no Athénée royal de Paris, em 1819, em que ele define o que é ser livre: "o objetivo dos modernos é a segurança dos privilégios privados; e eles chamam liberdade as garantias concedidas pelas instituições a esses privilégios" (CONSTANT, 1980, p.7). A nosso ver, essa aposta se justifica, pois, a problemática acercada liberdade positiva e negativa debatida por Berlim e Arendt, tem suas origens nessas reflexões do século XIX. A grande crítica de Constant, dirigida à concepção antiga de liberdade e que ainda hoje faz parte dos debates políticos, éticos e jurídicos, se alicerça na "completa submissão que os antigos concediam à autoridade do todo e não à do indivíduo" (CONSTANT, 1980, p.4). Esse risco se torna realmente muito sério, uma vez que todas as ações do âmbito privado estão sempre sub judice e constante vigilância da maioria, sendo assim, a tentativa de Constant é mostrar que sem a liberdade do sujeito nada seria concedido a ele sem a interferência dos demais. Sua liberdade de escolha sobre seu culto, suas doutrinas morais, políticas ou econômicas estariam condenadas ao fracasso e seus direitos inalienáveis não seriam protegidos da "tirania da maioria", portanto, diante desse risco que também se orienta a tese de Tocqueville, ao afirmar "o que mais me repugna na América não é a extrema liberdade reinante; é o pouco de garantia aí encontrado contra a tirania" (TOCQUEVILLE, 1979, p. 241). Do mesmo modo, nos assegura Berlin "a democracia pode desarmar uma dada oligarquia, um dado indivíduo ou conjunto de indivíduos privilegiados, mas ainda pode esmagar indivíduos tão impiedosamente quanto qualquer governante anterior" (BERLIN,1969, p. 26). Logo, nessa perspectiva, para Constant, os direitos políticos tão valorizados entre os antigos, apenas nos proporciona uma ínfima parcela de contentamentos que somente os antigos valorizavam. Portanto,

conclui-se que devemos ser bem mais apegados que os antigos à nossa independência individual. Pois os antigos, quando sacrificavam essa independência aos direitos políticos, sacrificavam menos para obter mais; enquanto que, fazendo o mesmo sacrifício, nós daríamos mais para obter menos. O objetivo dos antigos era a partilha do poder social entre todos os cidadãos de uma mesma pátria. Era isso o que eles denominavam liberdade. $O$ objetivo dos modernos é a segurança dos privilégios privados; e eles chamam liberdade as garantias concedidas pelas instituições a esses privilégios (CONSTANT, 1980, p.7).

No ideal liberal, o poder político não deve aderir a nenhuma concepção de bem. Mas, assegurar de que os próprios sujeitos baseados em suas noções sobre a vida boa, gozando de liberdade concretizem o que julgam melhor para eles, sem a interferência de terceiros ou do 
Estado. Estes devem ser imparciais em relação à diversidade das doutrinas razoáveis acerca do bem (Rawls) que os indivíduos busquem no uso da sua liberdade. Na ausência de um modelo de vida universal, a melhor saída proposta por esse ideal é uma apologia da democracia pluralista protegida pelo império das leis.

Retornando de nossa breve digressão, focaremos agora em alguns aspectos do célebre escrito de Isaiah Berlin, Dois Conceitos de Liberdade, como dito anteriormente, esse é um tema central na tradição política ocidental e, ao encontro de nosso intento especulativo, nos assegura Berlim "quase todos pensadores da história humana tem um grande apreço pela liberdade" (BERLIN, 1969, p.3). Porém, assim como os conceitos de felicidade e bondade, as opiniões sobre o tema em questão são muitas e díspares na história do pensamento. Devido a porosidade dessa matéria, o próprio Berlim faz seu recorte da querela em ponto e se propõe refletir sobre a noção de liberdade negativa (negative freedom) e como essa se relaciona com a liberdade positiva (positive liberty). Assim sendo, "as noções "positiva" e negativa" de liberdade desenvolveram-se historicamente em direções divergentes, nem sempre por passos logicamente respeitáveis, até entrarem por fim em conflito direto uma com a outra" (BERLIN, 1969, p.8).

Para esse autor, ser livre é viver sem as grades impostas pelos outros homens, ou seja, ser capaz de viver sem a interferência alheias nas minhas atividades e anseios. Em suma, a liberdade significa a capacidade que os homens podem agir e ser o que desejam sem a obstrução dos outros (BERLIN, 1969). A compreensão aceca da liberdade é também estendida por Berlim para outros campos da vida social e econômica. Citando os exemplos da privação da saúde e da ausência de dinheiro para um cidadão comprar um jornal, nosso autor denomina isso como sendo alguma forma de opressão ou escravidão econômica que coíbe e frustra qualquer possibilidade do indivíduo perseguir seus próprios desejos. Convém deixar claro que o sentido desta argumentação nasce no contexto onde o indivíduo fez se valer como titular de direitos precedentes à esfera política, sobretudo diante do Estado. Uma das defesas mais importantes desse ideal é a liberdade individual que passa a ser compreendida como espaço de ação em que o indivíduo não está impedido nem pelo Estado e nem pelos outros de fazer ou deixar de fazer aquilo que ele almeja - a chamada liberdade negativa.

A liberdade negativa é compreendida como ausência de empecilhos, grades ou reservas externas para que o indivíduo faça ou deixe de fazer somente aquilo que aspira realizar. É esta concepção de liberdade que Berlin vai defender. Segundo Ramos,

esta concepção tem por base um conceito negativo de liberdade e vincula-se à ideia da proteção jurídica dos direitos - o que resulta em compreender a cidadania como meio ou instrumento para o livre exercício do pluralismo ético, político e econômico dos cidadãos, sobretudo no âmbito privado da sociedade civil (RAMOS, 2010, p.268).

Logo, a compreensão negativa de liberdade de Berlin, adéqua o direito a um respeito à vida privada que a concepção positiva não possibilitaria. Elias clarifica essa problemática:

assim, a defesa da liberdade negativa e a consequente crítica à liberdade positiva implicam em uma crítica ao racionalismo. Berlin rejeita a possibilidade de que seja possível uma moralidade, um ideal ou princípio capaz de estabelecer um arranjo social que harmonize os diferentes valores importantes para o homem (ELIAS, 2012, p.5).

Portanto, segundo Berlin: "afirmamos que a liberdade negativa pode ser identificada pela linguagem da ausência de interferência, e a liberdade positiva, como a presença para a ação política" (BERLIN, 1969, p.8). 
Com as considerações anteriores, procuramos explicitar a dicotomia entre liberdades positiva e negativa, dirigindo nossa argumentação a fim de justificar uma certa preferência de Berlim pela concepção negativa de liberdade. Além disso, temos que levar em conta que o conceito de liberdade como não interferência apenas pode ser analisado em conjunto com o pluralismo e a importância da livre escolha no pensamento desse autor. Importa agora realçar que, mesmo com os argumentos apresentados e conscientes que Berlin atribui um grande valor à liberdade negativa, ressaltamos que a compreensão de liberdade de Berlin é um tema complexo. Interessa, não obstante, ressalvar a importância da contribuição de Berlin como um instrumento prático e conceitual de respeitável valor que sempre pode ser convocado para fornecer para pensamento político contemporâneo distintas compreensões sobre a liberdade.

Entre tantos pensadores que se dedicaram a pensar a sociedade contemporânea, Hannah Arendt (1906-1975), merece destaque pelo fato de conseguir decodificar como poucos os aspectos peculiares do século passado, tornando-a uma referência muito importante na Filosofia Política. A atualidade e complexidade dessa pensadora está no fato de que para os liberais ela foi vista como uma conservadora e para os conservadores foi interpretada como liberal. Por outro lado, há aqueles que a criticam por sua nostalgia irrealista do passado ou por ser uma revolucionária utópica. Vale advertir que a concepção arendtiana de política envolve uma ampla gama de conceitos que foram abordados na sua vasta obra filosófica, e, portanto, não temos a pretensão de esgotar os muitos horizontes do pensamento político da autora nesse pequeno esboço.

Arendt, na obra Sobre a Revolução (On Revolution) faz uma contraposição às tradições hegemônicas da década de 1960: o marxismo e o liberalismo. Nesse escrito, Arendt aponta que o equívoco do marxismo foi potencializar o debate sobre as questões sociais e explorar em menor proporção as questões políticas ao compreender a política apenas como um acontecimento social. A clássica tese marxista reconhece que apenas existe revolução quando a classe dos proletários deter o controle dos meios de produção. Todavia, a tese arendtiana não resume a política a questão social e adjetiva Karl Marx como o teórico dos "ditames das necessidades". Diferentemente, a autora interpreta a política como o empenho do número de adeptos na elaboração de um novo corpo político. Desse modo, "para Arendt, o verdadeiro espírito da política não diz respeito aos resultados sociais, mas à redescoberta dos valores da cidadania" (ACKERMAN, 2006. p. 286).

Por outro lado, Arendt vai de encontro a tradição liberal porque essa se concentra no bem-estar individual e esquece o espaço da ação pública. Arendt não recusa os direitos individuais, mas alerta que somente eles não sustentam a liberdade política e aponta o "perigo em confundir a felicidade pública e o bem-estar privado" (ARENDT, 2011, p. 173). Portanto, percebemos que Arendt almeja um caminho diferente das correntes supracitadas. Wellmer clarifica essa posição, para ele, a tese principal da autora é mostrar que "tanto democratas liberais quando marxistas não compreenderam o drama das revoluções modernas porque eles não entenderam que o era realmente revolucionário nessas revoluções era sua tentativa de criar uma constitutio libertatis" (WELLMER, 2000, p. 220).

Na obra A Condição Humana (The Human Condition), primeiramente, o retorno a essa obra se justifica porque esse texto é central para analisarmos a compreensão crítica que Arendt faz da modernidade e de seus desdobramentos políticos, sociais e econômicos. Para ela, as sociedades modernas foram constituídas na centralidade do trabalho e na vitória do animal laborans. Tal característica nos conduziu ao estabelecimento de padrões de comportamento e 
numa passividade mortal e estéril, e com isso "a vida individual tornara-se parte do processo vital, e o necessário era apenas trabalhar, isto é, garantir a continuidade da vida de cada um e de sua família" (ARENDT, 2016, p.399). Nesse mesmo sentido, a vitória desse modo de vida "é também a vitória de uma determinada mentalidade, mediada pela ideia de consumo e pelo cuidado da vida do homem na qualidade de espécie" (NASCIMENTO, 201, p.146). Essa problemática nos oferece elementos para pensarmos alguns limites e paradoxos do Estado liberal.

Para Arendt, os domínios do trabalho e da obra estão associados ao comando do oculto, ou seja, a esfera do privado onde o centro é o lar (oikia). Entre os gregos, nesse ambiente a condição do ser humano é a manutenção da vida sob os ditames do paterfamilias que governava a casa e conservava o domínio sobre os escravos e seus familiares. Já a ação exige a presença dos outros e se configura como legítimo espaço público da liberdade entre iguais "ao passo que o lar era o centro da mais severa desigualdade" (ARENDT, 2016, p.39). E segue, "o domínio da pólis, ao contrário, era a esfera da liberdade, e se havia uma relação entre essas duas esferas era a vitória sobre as necessidades da vida no lar constituía a condição óbvia para liberdade da pólis" (ARENDT, 2016, p.37). Vale ressaltar também, que segundo Arendt, na modernidade acontece a extensão da esfera privada sobre o espaço público. Nesse sentido, o governo se tornou apenas uma economia doméstica nacional ao reduzir a ação política à libertação da pobreza. A condição de miséria "coloca os homens sob o ditame absoluto de seus corpos, isto é, sob o ditame absoluto da necessidade" (ARENDT, 2011, p.93).

Do mesmo modo, a questão da liberdade é de suma importância na compreensão do pensamento arendtiano e para o confronto de ideias que nos propusemos. A tese central da autora, é que somente a liberdade pode instituir um espaço que garanta onde a própria liberdade possa habitar. A relação entre novo início e liberdade são temas centrais na compreensão do surgimento de uma nova ordem política. "Assim, o fundamental na era moderna é a convergência entre ideia de liberdade e a experiência de um novo início" (ARENDT, 2011, p.57).

Se Constant faz sua rejeição ao modelo de liberdade dos antigos, diferentemente, Arendt retoma o exemplo da pólis grega, uma vez para ela, é justamente na experiência da pólis que desaparece separação entre governantes e governados. Afinal, "a liberdade como fenômeno político nasceu com as cidades-estados gregas" (ARENDT, 2014, p.58). Essa narrativa não pode ser compreendida como se Arendt fizesse uma apologia nostálgica do que "foi" experiência entre os gregos. Ela também não pretende determinar categoricamente modelos morais ou jurídicos como deveria ser a política nos tempos contemporâneos. Arendt, à luz do passado, pretendeu refletir sobre o que "é" a política e principalmente o que ela ainda pode ser hoje e no futuro, diante de tantos fatos que eliminaram essa verdadeira experiência da vida humana. A autora pretende explicitar na experiência grega que o poder somente acontece quando os homens juntos decidem agir entre si, e nesse sentido, a liberdade e ação política são sinônimas.

$\mathrm{O}$ elemento predominante nesse encontro de homens livres e iguais faz da pluralidade e do conflito o germe do poder pois a experiência grega exigia um lugar onde os cidadãos pudessem se reunir. Esse era "o espaço político propriamente dito" (AREDNT, 2011, p.59). Portanto, se estamos corretos em nossa aposta teórica, julgamos que esse encontro com a Grécia Antiga tem por finalidade demonstrar que a identidade entre liberdade e política foi destruída com a expansão das teorias sociais e políticas da Idade Moderna. ${ }^{3}$ Por isso, "é o futuro que nos

\footnotetext{
${ }^{3}$ Sobre isso, vale uma ressalva da própria Arendt: "responsabilizar os pensadores da idade moderna, especialmente os rebeldes contra a tradição do século XIX, pela estrutura e pelas condições do século XX é ainda mais perigoso que injusto. As implicações manifestas no

KRETLE, Edson; ARAUJO, Ricardo Corrêa de. A superação da concepção liberal de liberdade em Hannah Arendt. Griot : Revista de Filosofia, Amargosa-BA, v.20, n.2, p.202-214, junho, 2020.
} 
impele de volta ao passado" (ARENDT, 2011, p.37), por conseguinte, "na verdade, é difícil e até mesmo enganoso falar de política e de seus princípios sem recorrer em alguma medida ás experiências da Antiguidade grega e romana" (ARENDT, 2011, p.200).

Para Arendt, a Antiguidade associou liberdade ao pensamento, nesse aspecto, o homem livre é aquele que pode discordar do mundo. Pensadores como Parmênides e Platão defendiam a vida do filósofo como uma existência devotada à reflexão pois defendiam que a vida teorética (bios theoretikos) é explicitamente oposta à vida política (bíos polítikos). Na análise de Arendt, esse afastamento da vida pública, continua com o cristianismo, uma vez que desde Paulo de Tarso, e posteriormente, Agostinho, o problema da liberdade se instala na arena da filosofia. Entretanto, a compreensão acerca do tema associou livre-arbítrio a liberdade; e a partir da tradição cristã, começamos a interpretar a liberdade como sendo uma experiência de solidão, ou seja, o relacionamento entre mim e mim mesmo. Baseados nessa vertente, "fomos habituados a compreender que a liberdade não pode ser vivida na ação coletiva, mas apenas no encontro com meu próprio eu" (ARENDT, 2011, p.204).

Se para Berlim e a tradição liberal, a liberdade negativa é valorizada quando preza pela não interferência dos governos e dos semelhantes nas decisões individuais, já Arendt propõe que a "cidadania é a ação política de indivíduos que buscam na esfera do espaço público da pluralidade a realização da liberdade" (RAMOS, 2010, p.267). Portanto, seguindo os passos de Ramos, reafirmamos que nossa aposta nesse esboço é que "este conceito pode ser interpretado como uma crítica diante das deficiências da tese liberal da cidadania, corrigindo as suas limitações" (RAMOS, 2010, p.267). Em outras palavras, apenas as liberdades civis não garantem a felicidade e a liberdade pública, uma vez que a busca de interesses pessoais e o desfrute de direitos privados também são possíveis em regimes tirânicos.

De acordo com Arendt, ser livre para ir e vir, está livre da fome, das restrições alheias são liberdade fundamentalmente negativas, porém, elas não constituem o alicerce da verdadeira liberdade que nossa autora defende. Pois, assim como no exemplo dos gregos, a essência da liberdade emerge em sua grandeza apenas quando acontece a participação e inserção dos humanos no debate público e nas decisões da cidade. A grande defesa de Arendt é que o Estado moderno não pode ser reduzido às liberdades civis, pois "se visasse apenas a garantia dos direitos civis, estaria visando não à liberdade, e sim a libertação de governos que haviam abusado de seus poderes e violado direitos sólidos e consagrados" (ARENDT, 2011, p.65).

Diferentemente de Berlin, para a pensadora alemã, o poder somente acontece na existência de espaços para a ação, no qual, os homens possam se mostrar uns aos outros. A decorrência dessa instituição é fruto de uma ação coletiva, fruto de consenso, ancorado em promessas mútuas e na pluralidade. Essa compreensão de poder é prática e não se sustenta nas apostas das teorias da soberania que dão fundamento aos estados liberais. Com isso, a nosso ver esse "empreendimento teórico permite superar as deficiências da concepção liberal, centrada na tese da cidadania como intitulação de direitos" (RAMOS, 2010, p.267). Nessa mesma linha, Ramos continua nos orientando que "o alcance e os limites da ação da cidadania estão definidos em leis, e a sociedade política é apenas o porta-voz dos direitos, cuja finalidade é a proteção dos interesses pré-políticos" (RAMOS, 2010, p.270).

O conceito de liberdade, na visão arendtiana, deve ser entendido como a capacidade que temos de criar novas formas de vida de ação na pluralidade. Ele possibilita então fundar e preservar corpos políticos. Situados na imanência, apenas criamos realidades subsumidas no tempo e no espaço, portanto, nada pode durar para sempre. "Assim, prometer e obrigar, unir e

evento concreto da dominação totalitária vão muito além das mais radicais ou ousadas ideias de quaisquer desses pensadores" (ARENDT, 2014. p.54).

KRETLE, Edson; ARAUJO, Ricardo Corrêa de. A superação da concepção liberal de liberdade em Hannah Arendt. Griot : Revista de Filosofia, Amargosa - BA, v.20, n.2, p.202-214, junho, 2020. 
pactuar são os meios de manter a existência do poder; sempre que os homens conseguem preservar o poder nascido entre eles durante qualquer gesto ou ação particular, já se encontram em processo de fundação" (ARENDT, 2011, p.228). Desse modo, a liberdade garante o início de novas experiências políticas, por isso, foi justamente esse espírito que na modernidade motivou os homens das revoluções francesa e americana instituírem um novo corpo político que garantisse a liberdade como meio e fim de sociedades livres.

É nesse sentido que Arendt critica Berlin e a tradição liberal, pois para ela, o liberalismo ao ter em seu cerne a ideia de que o Estado é um mal que deve ser suportado, eles não foram capazes de superar a convicção de que todo poder corrompe e que o progresso dos povos somente acontece pelo aumento da perda de poder, não importa qual seja sua origem. Para dizer de outra forma, Arendt esclarece que na noção liberal de liberdade, "o desejo de participação no governo só se justificaria pela necessidade de verificar e controlar essas tendências "injustificáveis" da natureza humana" (ARENDT, 2011, p.174). Para esclarecer sua afirmação, Arendt retoma como exemplo a Declaração de Independência dos Estados Unidos quando Jefferson, um dos Pais Fundadores da república americana, apresentou a busca da felicidade como um direito inalienável do homem. O equívoco dessa formulação consiste que os americanos confundiram a salutar diferença entre "direitos privados", típicos do liberalismo, com a "felicidade pública", e nesse horizonte criaram uma ideologia centrada na confusão entre felicidade pública e bem-estar privado. Sobre isso, Arendt diz em tom profético,

se essa estrutura tem uma base sólida capaz de resistir às palhaçadas frívolas de uma sociedade interessada no enriquecimento e no consumo, ou se cederá sob a pressão da riqueza, assim como as comunidades europeias cederam sob o peso da desgraça e do infortúnio, é algo que só o futuro pode dizer. Atualmente, os sinais que justificam a esperança empatam com os sinais que inspiram medo (ARENDT, 2011, p.185).

Desse confronto, o desejo "antipolítico" de ser desobrigado de qualquer dever e cuidado pela esfera pública sagrou-se vencedor. Desse modo, atualmente, somos herdeiros dessa maneira de pensar, e, é justamente esse o erro que explica e apatia e a indiferença da sociedade diante dos assuntos de interesse público. Diante dessa constatação e de encontro a ela, é que brota a defesa arendtiana de que são justamente "as atividades ligadas a esses assuntos não constituíam de maneira alguma um fardo; ao contrário, proporcionavam aos que se encarregavam delas um sentimento de felicidade que não encontrariam em nenhum outro lugar" (ARENDT, 2011, p.163).

Como caracteriza Arendt, o objetivo do liberalismo não é a participação cidadã na dimensão pública, mas a autonomia dos sujeitos na esfera privada da sociedade civil. Todo esse processo culmina na "despolitização" da sociedade, na qual, os conflitos sociais são oriundos da evidência atrelada à garantia da pessoa com privilégios e imunidades. Sendo assim, nessa visão de mundo, a cidadania é esvaziada do valor atrelado à participação política, que se reduz ao mecanismo da representação. Por sua vez, atribuímos apenas aos políticos "profissionais" os rumos da cidade, para que a sociedade civil, livre dessa obrigação tenha tempo suficiente para o desenvolvimento dos interesses privados. Torna-se assim evidente, que "a cabine de votação dificilmente pode ser vista com um lugar público; de fato, a única maneira de um cidadão atuar como tal, hoje, é como membro de um júri” (ARENDT, 2018, p.213).

$\mathrm{Na}$ concepção arendtiana, o poder desaparece quando a diversidade de opiniões e de ideias contrastantes é aniquilada. Os encontros e os debates públicos garantem a existência e a sobrevivência do próprio espaço da liberdade. 
Como descrito por Arendt, a liberdade se encontra na ação e no discurso entre os homens. Segundo ela, a liberdade na época moderna, equivocadamente foi é entendida muito distante da arena pública e afigurou-se como um mecanismo do restrito mundo privado. Disso resulta, o contraste que anteriormente estabelecemos com a concepção grega, na qual o homem livre não é aquele dominado como escravo ou como trabalhador amarrado à necessidade de garantir o seu pão cotidiano. Estes seres humanos eram vistos socialmente pela dimensão do labor e não pelo processo do falar (áneu lógou). Como mostra o comentador Celso Lafer, "o campo da política é o diálogo no plural que surge no espaço da palavra e da ação - o mundo público - cuja existência permite o aparecimento da liberdade" (LAFER, 2003, p.21).

$\mathrm{Na}$ opinião de Arendt, a legitimidade do poder se encontra na persuasão pela palavra e nas ações não violentas. Sobre isso, a autora afirma: "a ação e o discurso são circundados pela teia de atos e palavras de outros homens" (ARENDT, 2016, p. 233). A novidade das reflexões arendtianas nos possibilita acreditar que a promessa da política sempre poderá acontecer entre nós, porque a liberdade é a faculdade de interromper com o automatismo burocrático de qualquer outra forma de governo totalitário. Logo, o objetivo da sugestão de Arendt, é o "estabelecimento de instituições que garantem a liberdade para todos, e a fundação de um novo domínio público, chamado de república e oposto à monarquia, onde todo mundo, nas palavras de Jefferson, poderia se tornar "participante do governo" (AREDNT, 2018, p. 197).

Na busca de superar essa oposição entre os conceitos de liberdade, nossa aposta, é que em Arendt, existe a possibilidade de retomar a narrativa de um duplo sentido em ambas formas de liberdade, ou seja, harmonizar "o bem-estar privado e o direito à felicidade pública, a busca do bem-estar e ser um "participante nos assuntos públicos" (AREDNT, 2018, p. 178). Diversamente das tiranias e dos governos totalitários, uma boa forma de governo é aquela capaz de garantir direitos civis, e ao mesmo tempo incentivar a liberdade e a participação pública. Embora sejam extremamente importantes, apenas as garantias das liberdades civis e da escolha entre as várias concepções de bem, não faz uma sociedade ser livre. Portanto, os conceitos perderam sua dupla acepção e passaram a serem compreendidos apenas com o direito de o cidadão buscar seus interesses pessoais, "e assim agir conforme as regras do interesse próprio privado" (AREDNT, 2018, p. 197).

Segundo Arendt,

todo indivíduo, na privacidade de seu lar, está sujeito às necessidades da vida e tem o direito de ser protegido na busca de seus interesses privados; mas, em virtude de sua cidadania, ele recebe um tipo de segunda vida além de sua vida privada. Essas duas, a privada e a pública, devem ser consideradas separadamente, pois os propósitos e as preocupações são diferentes em cada caso" (AREDNT, 2018, p. 212).

E segue, "ao longo de sua vida, o homem se movimenta constantemente entre duas ordens diferentes da existência: ele se move dentro do que é seu, próprio, e também em uma esfera que é comum e ele e a seus concidadãos" (AREDNT, 2018, p. 212).

Nesse raciocínio, no capítulo VI de Sobre a Revolução, Arendt acenou como algo extremamente importante na organização política interna, o sistema de conselhos, nos quais a participação constante dos cidadãos nos afazeres cívicos cultive o horizonte constituinte do poder, contrabalanceado com a autoridade interpretativa do Supremo Tribunal e dos partidos políticos. Indubitavelmente, as possibilidades e os problemas que giram em torno dos elementos constitutivos de uma teoria dos conselhos é outra grande contribuição a ser explorada no pensamento de Arendt, no qual podemos encontrar no sistema de conselhos subsídios para o pensamento político contemporâneo. Assim Arendt diz:

KRETLE, Edson; ARAUJO, Ricardo Corrêa de. A superação da concepção liberal de liberdade em Hannah Arendt. Griot : Revista de Filosofia, Amargosa - BA, v.20, n.2, p.202-214, junho, 2020. 
os Comitês Revolucionários e os Conselhos dos Trabalhadores. Ambos reproduzem uma nova forma de exercício da política- o sistema de conselhos - que, já há mais de cem anos, tem surgido sempre que é permitido ao povo seguir, por alguns dias, semanas ou meses, suas próprias estratégias políticas sem a inspiração de um governo (ou programa partidário) "(AREDNT, 2018, p. 77).

Nesse sentido, vale ressaltar aqui também, a categoria ontológica de natalidade como um mecanismo necessário para findar ou fundar qualquer regime político. O nascimento de novas crianças estremece ou potencializa os alicerces dos corpos políticos. Assim sendo, "a ação é a atividade política por excelência, a natalidade, e não a mortalidade, pode ser a categoria central do pensamento político, em contraposição ao pensamento metafísico" (AREDNT, 2016, p. 11). As tentativas dos regimes tirânicos e totalitários de substituir o poder pela violência sempre visaram eliminar o "agir em concerto", que é a fonte do poder. Desse modo, tentamos mostrar a intrínseca relação entre liberdade, poder e natalidade no processo político.

Neste artigo, na esteira de Arendt, posicionamo-nos contrários à visão de liberdade de cunho Berlim compreendida como ausência de constrangimento por meio do qual o governo tem um lugar pouco significativo na administração da vida pública, considerando ainda que o mesmo existe apenas com um aparato racional-legal para defender os interesses particulares dos indivíduos. Por conseguinte, dialogamos com a análise de Nascimento, pois para ele a tradição jurídica e política da modernidade é baseada na valorização do ser humano enquanto sujeito fonte da verdade. Com isso, o pensamento moderno liberal se filiou os direitos humanos aos direitos do indivíduo natural, o que resultou no individualismo da sociedade de massa. Portanto, resta-nos dizer que

o fracasso desse projeto implica no desamparo da proteção ao homem pelo simples fato de ser homem ou pelo fato de ter se tornado um sujeito. $O$ apelo ao racional e à consagração de determinados valores perde o seu vigor diante do aumento da barbárie (NASCIMENTO, 2013, p.134).

\section{Considerações finais}

Nessa tentativa teórica, pretendemos desvelar em Arendt as possibilidades da liberdade positiva, compreendida como berço de virtudes cívicas, bem como da ação política ancorada na liberdade e defendida num governo de leis, logo, isso aproxima nossa interpretação do pensamento de nossa autora da tradição republicana. Por isso, buscamos demostrar em Arendt as possibilidades da liberdade positiva ${ }^{4}$ (political freedom), compreendida como berço de virtudes cívicas, bem como a participação política ancorada na liberdade e defendida no governo constitucional. Desse modo, reafirmamos nossa aposta inicial ao mostrar que, em Arendt, "o prolongamento dessa busca para além satisfação do indivíduo deságua na noção de felicidade pública, isto é, no gosto de reivindicar participação na condução dos assuntos públicos e se preocupar com o bem-estar comum" (ARENDT, 2018, p.13).

Outro ensinamento de Arendt é aquele que diz que a capacidade de iniciar dos homens está diretamente relacionada à nossa habilidade de criar novas realidades, isto é, diz respeito à nossa liberdade política de (re) começarmos novos mundos. Se de um lado essa maneira de compreender a fundação expõe sua posição em favor da liberdade como força criadora e mostra

\footnotetext{
4 Nesse aspecto, seguimos a orientação: “Arendt's understanding of freedom is not, as sometimes suggested, simply a reflection of positive as opposed to negative liberty in the sense described by Isaiah Berlin in his celebrated essay. For this reason, I use the term 'political freedom' rather than 'positive freedom"” (WILKINSON, 2012, p. 58).
} 
a que tradição se filia nossa autora, como também sua oposição ao liberalismo de Berlin e em certa medida à herança liberal. Portanto, novamente enfatizamos que "a liberdade negativa dos liberais não dá conta de oferecer respostas às crises de legitimação das democracias contemporâneas, porque o problema central das democracias não é o problema da interferência (ou da falta de neutralidade), mas o problema da dominação" (FILGUEIRAS, 2012, p.233).

Em Arendt, a afirmação fundamental é a de que a liberdade é a razão de ser da política. Deste modo, a tese central da autora, como pensadora da política, é que somente a liberdade pode instituir um espaço que garanta um lugar no qual a própria liberdade possa habitar. A relação entre cidadania e são temas centrais na compreensão do surgimento de uma nova ordem política. Podemos arriscar que o valor da liberdade no pensamento de Arendt deve-se ao fato de que, diante dos tempos de terror e de sua experiência pessoal, ela tenha sido levada a interpretar e acreditar que a liberdade é a faculdade que sempre permanece, mesmo quando vivemos tempos políticos petrificados. A liberdade é a pura disposição de iniciar e inspirar todas as atividades humanas e que constitui a fonte de todas as coisas grandes e belas na dimensão política.

Portanto, a duração do reich milenar, a ditadura do proletariado e o fascismo italiano conseguiram a dominação das massas porque se dedicaram a erradicar essa fonte oculta da existência humana, já que com o fim da liberdade a ação política torna-se incapaz e toda a diversidade das experiências humanas se transforma numa engrenagem automática e petrificada. Que desumanas experiências dos regimes totalitários e dos constantes ataques ao Estado Democrática de Direito sejam algo que impulsionem o crescimento das rosas da liberdade, do perdão, da ação e da pluralidade. As escolhas humanas são como sementes e a qualidade dos frutos políticos do amanhã dependerá e será resultado do que semeamos hoje. Por conseguinte, "o desafio permanente de uma sociedade é se ocupar do bem comum sem violar os direitos dos cidadãos individuais e que, felizmente, os dois interesses geralmente coincidem" (ARENDT, 2018, p.214). Por fim, “a questão se o fim do governo era a prosperidade ou a liberdade nunca foi resolvida" (ARENDT, 2011, p.183). 


\section{Referências}

ABBAgnano, Nicola. Dicionário de Filosofia. São Paulo: Martins Fontes, 2014.

ACKERMAN, Bruce. Nós, o povo soberano: fundamentos do direito constitucional. Belo Horizonte: Del Rey, 2006.

ADVERSE, Helton. Arendt e a democracia representativa. Pensando - Revista de Filosofia. Piaui, v. 9, $\mathrm{n}^{\circ}$ 17, p.139-155. 2018.

ARENDT, Hannah. Sobre a Revolução. São Paulo: Companhia das Letras, 2011.

ARENDT, Hannah. A condição humana. Rio de Janeiro: Forense Universitária, 2016.

ARENDT, Hannah. A Vida do Espírito: o pensar, o querer, o julgar. Rio de Janeiro: Instituto Piaget, 2017.

ARENDT, Hannah. Entre Passado e o Futuro. São Paulo: Perspectiva, 2014.

ARENDT, Hannah. Origens do totalitarismo: antissemitismo, imperialismo, totalitarismo. Copyright Mary Mc Carthy West, 1979.

ARENDT, Hannah. Sobre a Violência. Rio de Janeiro: Civilização Brasileira, 2016.

ARENDT, Hannah Ação e a busca da felicidade. Rio de Janeiro: Bazar do Tempo, 2018.

BERLIN, Isaiah. Two concepts of liberty: four Essays On Liberty. Oxford, England: Oxford University Press, 1969.

CONSTANT, Benjamin. Da liberdade dos antigos comparada à dos modernos. Tradução de Loura Silveira. Paris, 1980

CORREIA, Adriano. Hannah Arendt e a modernidade: política, economia e a disputa por uma fronteira. Rio de Janeiro: Forense Universitária, 2014

CORREIA, Adriano. Quem é o animal laborans de Hannah Arendt? Revista de Filosofia Aurora, Curitiba, v. 25, n. 37, p. 199-222, jul-dez. 2013.

ELIAS, Maria Lígia G. Granado Rodrigues. Isaiah Berlin e o debate sobre a liberdade positiva e a liberdade negativa. In: $8^{\circ}$ Encontro da $A B C P, 2012$, Gramado: Anais. Rio Grande do Sul.

FILGUEIRAS, Fernando de Barros. Tolerância, república e democracia. Teoria e sociedade. São Paulo, $\mathbf{n}^{\mathrm{o}}$ 20. p.218-243, jan-jun. 2012

LAFER, Celso. Hannah Arendt: pensamento, persuasão e poder. São Paulo: Paz e Terra, 2003. LOCKE, John. Segundo tratado sobre o governo. São Paulo: Abril Cultural, 1973. (Coleção Os Pensadores).

MILL, John Stuart. Sobre a liberdade. Rio de Janeiro: Vozes, 1991.

NASCIMENTO, Daniel Arruda. Biopolítica e direitos humanos: uma relação revisitada guiada pelo cortejo da ajuda humanitária. Revista de Filosofia Aurora. Curitiba, v. 25, n. 3, p. 131-150, jul/dez 2013.

RAMOS, Cesar Augusto. Hannah Arendt e os elementos constitutivos de um conceito não liberal de cidadania. Revista de Filosofia Aurora. Curitiba, v. 22, n. 30, p. 267-296, jan-jun. 2010 RAWLS, John. O liberalismo político. Lisboa: Presença, 1997.

RAWLS, John. Justiça e democracia. São Paulo: Martins Fontes, 2000.

TOCQUEVILLE, Alexis. A Democracia na América. Editora Abril Cultural, 1979 (Os Pensadores).

VITA, Álvaro de. Sociedade democrática e tolerância liberal. Novos Estudos, n 84, p. 61-81, julho 2009.

WELLMER, Albrecht. Arendt on revolution. In: Dana Villa (org). The Cambridge Companion to Hannah Arendt. Cambridge: Cambridge University Press, 2000. 
WILKINSON, Michael. Between Freedom and Law: Hannah Arendt on the Promise of Modern Revolution and the Burden of 'The Tradition'. In: GOLDONI, Marco; MCCORKINDALE, Chris (orgs.), Hannah Arendt and the Law. Oxford and Portland, Hart Publishing (35- 61).

Contribuição dos(as) autores(as): Edson Kretle e Ricardo Corrêa de Araujo participaram da pesquisa, discussão e redação do artigo. Ambos aceitaram e aprovaram a versão final do texto.

Autor(a) para correspondência: Edson Kretle, Rua Elizabeth Minete Perim, No 0, Ifes, 29375-000, Venda Nova do Imigrante - ES. Brasil. edson.santos@ifes.edu.br 